\title{
Patients Attitudes' Toward Chairside Medical Screening in a Dental Setting
}

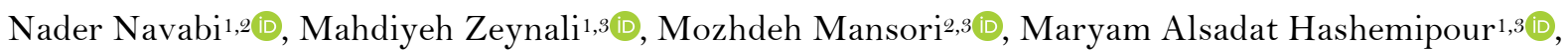

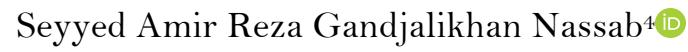

\begin{abstract}
${ }^{1}$ Department of Oral Medicine, Dental School, Kerman University of Medical Science, Kerman, Iran.
${ }_{2}^{2}$ Kerman Dental and Oral Diseases Research Center, Kerman University of Medical Sciences, Kerman, Iran.

${ }^{3}$ Kerman Social Determinants on Oral Health Research Center, Kerman University of Medical Sciences, Kerman, Iran.

${ }^{4}$ Medical School, Kerman University of Medical Science, Kerman, Iran.
\end{abstract}

Author to whom correspondence should be addressed: Maryam Alsadat Hashemipour, Department of Oral Medicine, School of Dentistry, Kerman University of Medical Sciences, Kerman, Iran. Phone: +98 3412118074. E-mail: m_s_hashemipour@yahoo.com.

Academic Editors: Alessandro Leite Cavalcanti and Wilton Wilney Nascimento Padilha

Received: 08 August 2019 / Accepted: 13 April 2020 / Published: 08 May 2020

How to cite this article: Navabi N, Zeynali M, Mansori M, Hashemipour MA, Nassab SARG. Patients attitudes' toward chairside medical screening in a dental setting. Pesqui Bras Odontopediatria Clín Integr. 2020; $20: e 4880$. https://doi.org/10.1590/pboci.2020.080

\begin{abstract}
Objective: To assess patient's attitudes toward chairside medical screening in a dental setting. Material and Methods: In this descriptive-analytic study, subjects referring to the dental school, dental offices, and clinics of Kerman were evaluated. Each subject filled a questionnaire containing demographic data, patient's attitude towards the performance of examination and the medical status of the subjects. The questionnaire consisted of seven main questions and the subjects were asked to rate them from very important (score 5) to not important at all (score 1). Wilcoxon and Mann-Whitney tests and t-test were used. Friedman's nonparametric analysis of variance was used to compare response items within each question. Results: Screening for medical conditions by dentists was important for most of the participants, and it was important for them to be monitored for their medical condition by the dentists. The majority of patients had the will to be screened for each medical condition by the dentists. Male subjects stated skillfulness and professionality $(88.4 \%)$ as the most important characteristics of the dentist and compassion as the least important one (56.2\%). Female subjects stated knowledge of the dentists (96.3\%) as the most essential characteristic and compassion as the least important one (85.8\%). The will to undertake screening tests was higher in elder subjects. Conclusion: Dental patients have a positive attitude for medical conditions screening. Screening for medical conditions in a dental setting is a new approach, which might be an important contributor to disease control in the general population.
\end{abstract}

Keywords: Attitude to Health; Health Knowledge, Attitudes, Practice; Dentistry; Early Diagnosis. 


\section{Introduction}

A large number of people of a wide age range, from children to geriatric patients, undergo dental treatment procedures every day. A number of these individuals have some systemic conditions. Various studies have shown that of 10,000 dental patients, 16 are prone to bacterial endocarditis; of 2000, 400 have high blood pressure; of 100, 12 have gastrointestinal disorders, and of 1000, 12 have asthma [1,2].

Previous studies have demonstrated that $37.2 \%$ of the people referring to the dentists in the Netherland have medical issues with the highest prevalence attributed to cardiovascular and respiratory (54\%), cerebral (12\%), and epileptic problems (2\%) [1,2]. Furthermore, 16 subjects from 10,000 dental patients are prone to develop bacterial endocarditis; 400 from each 2000 have hypertension, 12 out of 100 have digestive issues and 30 out of 1000 have asthma [3,4].

American Heart Association (AHA) has recently claimed that the prevalence of cardiovascular diseases would increase by $10 \%$ from 2010 to 2030 , and disease-costs will increase up to $61 \%$ in the same period [5]. Besides, the Center for Disease Control (CDC) has stated that the prevalence of diabetes and prediabetic conditions would increase from $14 \%$ in 2010 to $21-33 \%$ in 2050 [6,7]. The increase in the prevalence of diabetes and cardiovascular disease and their related disease costs highlights the need for preventive strategies to effectively control these epidemic diseases.

One of the vital steps in prevention in the health systems is the early diagnosis of high-risk subjects. Further preventive measures could be made through this early diagnosis, and the severity of disease could be controlled through these measures [8].

Therefore, one of the key steps in providing successful dental treatment for the patients is to evaluate the nature, severity, and stability of medical issues of the patient. For example, obtaining a simple radiographic image from a subject with congestive heart disease (CHD) is of little risk, if any at all, but the extraction of a tooth in an anxious patient with a moderate level of CHD is hazardous. Thus, each dentist must evaluate the physical and psychological status of the subjects while performing invasive and traumatic procedures on the subjects. Therefore, the main point in each dental examination visit is to evaluate the medical history of the patients [4].

Based on a pre-supposed principle, each dental patient undergoing any kind of treatment must be evaluated medically. The medical history consists ofa systematic review of the chief complaint and primary complaint of the patient, precise history of the patient problem, past and present medical status of the patient, family history of any medical problems and a review of the symptoms and demographic characteristics of the subjects $[2,4,9,10]$.

Screening for medical problems in dentistry has become very important in the last few years and is an appropriate method for early diagnosis and prevention of medical issues. Studies have demonstrated that the majority of dentists feel the need for medical screening of the subjects, especially in subjects with an unknown medical history, and many dentists claim their interest in guiding the patients and informing them of their possible medical issues such as obesity [11,12].

Research from New Zealand demonstrated that almost all of the general dentists have a role at stages of diabetes control, though most of them were not interested in being involved [13]. In addition, previous studies have demonstrated the positive consequences of screening of cardiovascular diseases and diabetes by dentists [14,15]. A review of the literature and analyzing the behavior of patients referring to the oral medicine departments show that some subjects are not interested in precise medical history and would not like 
to be evaluated medically. This question rises that do the patients have any attitude for medical screening during their dental visit and how much these subjects are important to them $[16,17]$.

Therefore, the objective of the current study was to evaluate the opinion of subjects referring to the dental school, private offices and clinics of Kerman, Iran, regarding the examinations and medical questions asked from them during their dental visit in the year 2013-2015.

\section{Material and Methods}

\section{Study Design and Sample}

In this descriptive-analytic study, subjects referring to the dental school, dental offices, and clinics of Kerman, Iran, were evaluated. A total of 400 subjects referring to the specified locations were enrolled in the study. The nature and objective of the study provided an opportunity for the subjects enrolled to exit from the study at any point they wanted to.

\section{Data Collection}

Each subject filled a questionnaire containing demographic data, patient's attitude towards the performance of examination and the medical status of the subjects. The questionnaire consisted of seven main questions and the subjects were asked to rate them from very important (score 5) to not important at all (score $1)$.

To validate the questionnaire, it was rated by seven experts from Kerman Dental School and they were asked to score the questions from totally appropriate to totally inappropriate. The level of each question and its comprehensibility was discussed by the subjects. After this step, 11 questions were rated adequate and two questions were removed due to their inappropriateness. To obtain the reliability of the questions, the questionnaire was filled by 20 subjects within two weeks. Cronbach's Alpha was 0.75, which was good, and the reliability was 0.71 to 0.89 . After final editing the questionnaire, it was filled by the subjects.

Data Analysis

Data were analyzed using IBM SPSS software, version 18 (IBM Corp., Armonk, NY, USA). T-test, ANOVA, Wilcoxon-Mann-Whitney and Chi-square were used to analyze data. $\mathrm{p}<0.05$ was considered statistically significant.

Ethical Aspects

Our research approved by ethics committee of vice deputy of research at Kerman University (Protocol No. IR.KMU.REC.1395.254). The aims of the study were explained for each subject, and they participated voluntarily in the study.

\section{Results}

The average age of the participants was $28.12 \pm 12.8$ years ranging from 18 to 64 years. Most participants were women (63\%), > 35 years old (69.3\%), employees (94.3\%) and with academic education (56.7). (Table 1). A total of $46.8 \%$ had at least one dental visit, $34.8 \%$ had two dental visits, $14.7 \%$ had more than 2 and $3.7 \%$ had no dental visit in the last year. 


\section{Table 1. Demographic characteristics of the study population.}

\begin{tabular}{lcc}
\multicolumn{1}{c}{ Variables } & N & \% \\
\hline Gender & 148 & \\
$\quad$ Male & 252 & 37.0 \\
Female & & 63.0 \\
Age (Years) & 123 & \\
$\quad<35$ & 277 & 30.7 \\
$\quad>35$ & & 69.3 \\
Occupation & 377 & \\
$\quad$ Employed & 23 & 94.3 \\
$\quad$ Unemployed & & 5.7 \\
Education & 173 & 43.3 \\
$\quad \leq$ Academic Education & 227 & 56.7 \\
$\quad>$ Academic Education & & \\
\hline
\end{tabular}

Screening for medical conditions by dentists was important for most of the participants, and it was important for them to be monitored for their medical condition by the dentists. The majority of patients had the will to be screened for each medical condition by the dentists.

Answers to the questionnaire categorized by gender and age and the following points were not significant different between male and female: Importance of medical conditions screening and monitoring (men: 83.7\% vs. women: 93.9\%); The will to be screened and discuss the results with the subjects (men: $95.1 \%$ vs. women: $97.1 \%$ ); The intention to refer to the physician (men: $83.7 \%$ vs. women: $82.6 \%$ ); The will to obtain oral fluids sample (men: $27.4 \%$ vs. women: $33.1 \%$ ); The importance of confidentiality of medical conditions (men: 99.1\% vs. women: 97.1\%); The importance of insurance coverage for a specific procedure (men: $99.1 \%$ vs. women: 97.8\%); The importance of tests not requested by Physician (men: 73.7\% vs. women: 72.1\%); The importance of data confidentiality for each subjects and consequences of data exposure (men: $99.1 \%$ vs. women: 83.8\%); The most requested test was hypertension (95.1\%) and the least requested was HIV test (36.1\%).

The oral fluid sampling and blood collection from fingertips were noticeably low in the subjects. The most requested procedure was immediate medical tests and the least requested procedure was to send out samples to the commercial laboratories. The majority of the participants were willing to be informed regarding the results of the tests. For all individuals, confidentiality and data security and insurance coverage were important. Though it was important for most of the subjects that not one physician performs all the procedures. Most of the subjects claimed that they would have a better concept of their dentist if he performed screening.

Male subjects stated skillfulness and professionality (88.4\%) as the most important characteristics of the dentist and compassion as the least important one (56.2\%). Female subjects stated knowledge of the dentists $(96.3 \%)$ as the most essential characteristic and compassion as the least important one (85.8\%). The will to undertake screening tests was higher in elder subjects.

Results revealed that tests with faster results are more important for those with a lower level of education in comparison to the high level of educated subjects. Besides, the will to perform all tests (blood pressure, diabetes, hepatitis, cardiovascular diseases, thyroid diseases, and HIV) was higher in low educated subjects in comparison to the subjects with higher educations. As demonstrated, subjects with a job had more appropriate answers to the questions.

Though all the subjects had a positive attitude to screening and monitoring of medical conditions by dentists, the average score and mean rank was lower for male subjects, those with lower education levels and lower age and subjects who were jobless (Tables 2 and 3 ). 
Table 2. Association between gender and education with the mean score.

\begin{tabular}{|c|c|c|c|c|c|c|}
\hline \multirow{3}{*}{ Questions } & \multicolumn{6}{|c|}{ Mean Score ${ }^{\ell}$} \\
\hline & \multicolumn{3}{|c|}{ Gender } & \multicolumn{3}{|c|}{ Education } \\
\hline & Male & Female & p-value $\ddagger$ & $\leq$ Diploma & $>$ Diploma & p-value $\ddagger$ \\
\hline How important is it that the dentist inform the patients regarding their undetected medical condition? & 1.12 & 1.02 & 0.05 & 1.45 & 1.25 & 0.07 \\
\hline How important is it for you that your dentist examines you thoroughly for your known medical condition? & 1.32 & 1.12 & $0.02^{*}$ & 1.25 & 1.12 & 0.06 \\
\hline Which of the following you will to undergo during a dental visit? & 1.45 & 1.12 & $0.02 *$ & 2.12 & 1.85 & $0.04 *$ \\
\hline Which of the procedures you would like your dentist to perform in a single visit? & 1.56 & 1.45 & 0.05 & 1.85 & 1.45 & $0.04 *$ \\
\hline Which of these samples or data,to detect your medical status, you would provide for your dentist? & 1.25 & 1.12 & 0.07 & 1.47 & 1.21 & 0.08 \\
\hline Which of these medical examination are important for you during a single dental visit? & 1.45 & 1.23 & 0.05 & 1.26 & 1.412 & 0.06 \\
\hline $\begin{array}{l}\text { If your dentist wants to perform these medical examinations for you during dental visit, which of these is } \\
\text { important for you considering the procedure? }\end{array}$ & 1.85 & 1.56 & $0.04 *$ & 2.14 & 1.45 & 0.05 \\
\hline How much would you pay for each of the medical tests if performed during a dental visit? & 3.12 & 2.98 & 0.06 & 2.15 & 2.10 & $0.01 *$ \\
\hline
\end{tabular}

Mean Score $\mathscr{E}=$ Based on the response scores (1-5) for each element; $¥$ Wilcoxon an Mann-Whitney test; *Statistically significant.

\section{Table 3. Association between age and job with the mean score.}

\begin{tabular}{|c|c|c|c|c|c|c|}
\hline \multirow{3}{*}{ Questions } & \multicolumn{6}{|c|}{ Mean Score ${ }^{\ell}$} \\
\hline & \multicolumn{3}{|c|}{ Age } & \multicolumn{3}{|c|}{ Occupation } \\
\hline & $<35$ & $>35$ & p-value $\ddagger$ & Employed & Unemployed & p-value $\ddagger$ \\
\hline How important is it that the dentist inform the patients regarding their undetected medical condition? & 1.45 & 1.55 & 0.05 & 1.25 & 1.54 & $0.01 *$ \\
\hline How important is it for you that your dentist examines you thoroughly for your known medical condition? & 1.87 & 1.25 & $0.02 *$ & 1.59 & 1.65 & 0.05 \\
\hline Which of the following you will to undergo during a dental visit? & 1.25 & 1.32 & 0.08 & 1.25 & 1.23 & 0.07 \\
\hline Which of the procedures you would like your dentist to perform in a single visit? & 2.15 & 2.10 & 0.06 & 1.06 & 2.15 & $0.01 *$ \\
\hline Which of these samples or data,to detect your medical status, you would provide for your dentist? & 2.15 & 1.58 & $0.01 *$ & 1.89 & 2.18 & $0.01 *$ \\
\hline Which of these medical examination are important for you during a single dental visit? & 1.95 & 1.25 & $0.01^{*}$ & 1.47 & 1.98 & $0.01 *$ \\
\hline $\begin{array}{l}\text { If your dentist wants to perform these medical examinations for you during dental visit, which of these is } \\
\text { important for you considering the procedure? }\end{array}$ & 1.65 & 1.78 & 0.05 & 1.29 & 1.58 & 0.06 \\
\hline How much would you pay for each of the medical tests if performed during a dental visit? & 3.12 & 2.15 & $0.01 *$ & 2.15 & 3.12 & $0.01 *$ \\
\hline
\end{tabular}

Mean Score ${ }^{\ell}=$ Based on the response scores (1-5) for each element; ${ }^{+W}$ Wilcoxon an Mann-Whitney test; *Statistically significant. 


\section{Discussion}

One of the critical steps in prevention and health care is the early diagnosis of the high-risk population that their disease could be prevented or controlled through this early detection [18]. American heart association (AHA) has stated that a 10 and $61 \%$ increase would happen in the prevalence and costs of cardiovascular disease untill 2030 [5].

It is estimated that $40.5 \%$ of the US population would suffer from a kind of cardiovascular problem [19], and the majority of this population would not be aware of their disease [20]. Furthermore, the prevalence of diabetes and prediabetes would increase from $14 \%$ in 2010 to $21-33 \%$ in $2050[6,7]$, and the number of US population with diabetes would be 26 million people.

It is assumed that more than one-third of the world population and 79 million adult Americans are at the prediabetes stage. Twenty-seven percent of diabetic patients are not aware of their disease and $35 \%$ of prediabetic subjects are unaware of their disease [21,22].

High blood pressure is a global issue and is present in $26.4 \%$ of the adult population worldwide and it would increase by $60 \%$ in 2025 [5,23]. This increased estimation in prevalence and related costs of the disease for diabetes and cardiovascular diseases needs a high level of preventive programs for effective control of these growing epidemics. Previous studies have demonstrated the effects and advantages of screening for coronary heart disease and diabetes patients by oral health care providers [14,15].

In many countries, dentists regularly visit their patients, and $60 \%$ of people visit their doctors annually [24]. More than half of these subjects have not visited their physician in the last year [25]. Dentists' role in the control of the disease is one of the most recent objectives of a dental profession defined by WHO, which states that by the medical visit of the patients, the population of subjects receiving preventing measures would increase [8]. Thus, dentists are an essential part of the aggregation of health care provider strategy for control of diseases.

Studies have demonstrated that implementing a screening program for medical conditions in the dental office is an effective measure to prevent and control diseases. It has been shown that most of the dentists are willing to screen patients for the unknown diseases and inform them of their medical conditions such as obesity [11,12]. Research from New Zealand has reported that nearly all the general dentists are involved in different phases of the diabetes control program, though most of them arenot willing to participate [13].

The current study evaluated the attitude of patients regarding the screening of medical conditions by the dentist. Medical screening has been performed for more than 600 years and has a profound history. Preclinical diagnosis of a disease is an important part of modern medicine and general health and has led to great achievements in medical sciences [26]. Most of the participants were willing to be screened for their undetected medical conditions and monitor their disease, which is consistent with previous studies [18,23].

A positive attitude of the patients for medical examination as part of a dental visit has also been shown in other studies as well [27,28]. In a previous study, they demonstrated that medical screening of the patients in the dental profession is acceptable if they receive enough medical education and dentists performing such examinations and screening programs must be educated for these conditions [28].

Results of the current study revealed that the majorityof subjects are willing to be involved in an active discussion regarding the result of their test during their dental visit and then be referred to the physician. Furthermore, most of them were willing to undergo different paraclinical examinations such as blood pressure and blood sugar, though a few were willing to undergo fingertip blood sampling. 
It has been previously shown that participants are willing to hear the results from their dentists and even those without abnormal test results claimed their will to be informed of the results [23]. Participants in the US had a high positive response to obtaining a fingertip blood sample [8].

In the study performed on New Zealand dentists, they had a lower will to fingertip blood sampling in comparison to the US patients. Results also demonstrated a positive attitude for diabetes and HIV testing [27,29]. A questionnaire-based study in adults with diabetes in England showed that 53.5\% of the participants supported their contribution and involvement of dentists in the diabetes screening program and $20.9 \%$ what the will to pay the fees for diabetes control in the dental environment [30].

Some studies have revealed that patients claimed that dentists are not able to diagnose medical conditions, and the objective of screening for medical conditions by dentists is solely the diagnosis of high-risk subjects [20,23].

As participants stated, this kind of screening might lead to false-positive results, especially in the case of hypertension due to the "white coat" phenomenon, which is due to the anxiety in a dental environment. This false diagnosis might lead to unnecessary visits, burdening upon the health care system and unnecessary anxiety in some subjects.

Despite this, studies in the US have demonstrated that high blood pressure measures in the dental office might have another reason, so by examination of patients with high blood pressure, dentists might help them [31]. The difference in this issue might be related to education, the degree of education, demands and needs in the studied populations and weak knowledge regarding the importance of self oral health care and limited knowledge of the consequence of neglecting oral hygiene related to the systemic diseases.

Responders stated that dentists performing medical screening procedures improve their insight regarding professionalism, knowledge, competence, and compassion and they were willing to pay upto $20 \$$ for screening procedures, which is consistent with other studies [18,23].

Getting assured regarding confidentiality was the most important topic for the patients and the fact that tests were performed by a dentist and not a physician was significantly more important than the clinical time, which shows the unacceptance of screening by dentists [18,23].

The difference in responses between different studies might be due to the difference in their access to primary care physicians. In addition, the difference might be due to the concepts of patients to the treatment facilities. Furthermore, the lower age of the participants in the current study might alter their response to medical screening procedures. No data regarding insurance coverage and access to the physician was not obtained from the participants, which might affect their attitude to the medical screening in a dental setting. General implementation of medical screening would need focused educational programs for oral health care providers and improving patient compliance and a decrease in the worries regarding medical screening in the dental profession.

\section{Conclusion}

Dental patients have a positive attitude for medical conditions screening. Screening for medical conditions in a dental setting is a new approach, which might be an important contributor to disease control in the general population.

\section{Authors' Contributions}




\begin{tabular}{|c|c|c|}
\hline $\mathrm{NN}$ & (iD) $0000-0001-6321-0089$ & Methodology, Investigation and Writing - Review and Editing. \\
\hline MZ & (D) $0000-0002-3758-7226$ & Investigation, Formal Analysis and Writing - Review and Editing. \\
\hline MM & (iD) $0000-0001-9026-7590$ & Writing - Review and Editing. \\
\hline MAH & (iD) $0000-0002-1075-4020$ & $\begin{array}{l}\text { Conceptualization, Methodology, Formal Analysis, Supervision, Writing - } \\
\text { Original Draft Preparation and Writing - Review and Editing. }\end{array}$ \\
\hline SARN & (iD) $0000-0003-4730-9737$ & Methodology, Investigation and Writing - Review and Editing. \\
\hline
\end{tabular}

\section{Financial Support}

None.

\section{Conflict of Interest}

The authors declare no conflicts of interest.

\section{References}

[1] Fernández-Feijoo J, Garea-Gorís R, Fernández-Varela M, Tomás-Carmona I, Diniz-Freitas M, Limeres-Posse J. Prevalence of systemic diseases among patients requesting dental consultation in the public and private systems. Med Oral Patol Oral Cir Bucal 2012; 17(1):e89-93. https://doi.org/10.4317/medoral.17313

[2] Hashemipour M, Ataie Z, Orandi S. The knowledge and practice of dentists about medical emergency in private dental offices. J Dent 2009; 10(3): 222-33.

[3] Greenburg M, Glick M. Burket's Oral Medicine.12th ed. Hamilton: BC Decker; 2018. pp. 238, 258, 352, 427.

[4] Little JW, Falace DA, Miller CS, Rhodus NL. Dental Management of the Medically Compromised Patient. 11th ed. St. Louis: Elsevier Mosby; 2018. pp. 2-18.

[5] Heidenreich PA, Torgdon JG, Khavjou OA, Butler J,Dracup K, Ezekpwitz MD, et al. Forecasting the future of cardiovascular disease in the United States. A policy statement fromthe American hearth association. Circulation 2011; 123(8):933-44.

[6] Centers for Disease Control and Prevention. Division of news and electronic media.number of americans with diabetes rises to nearly 26 million. More than a third of adults estimated to have diabetes. Available from: http: //www.cdc.gov/Features/Diabetes Fact Sheet/Get the Facts on Diabetes. [Accessed on August 26, 2011].

[7] Boyle JP, Thompson TJ, Gregg EW, Barker LE, Williamson DF. Projection of the year 2050 burden of diabetes in the US adult population: dynamic modeling of incidence, mortality and prediabetes prevalence. Popul Health Metr 2010; 8:29. https://doi.org/10.1186/1478-7954-8-29

[8] Centers for Disease Control and Prevention. Department of Health and Human Services. Healthy People 2020. Available from: https://www.healthypeople.gov/2020/topics-objectives. [Accessed on December 10, 2018].

[9] Abraham-Inpijn L, Russell G, Abraham DA, Bäckman N, Baum E, Bullón-Fernández P, et al. A patient administered Medical Risk Related History questionnaire (EMRRH) for use in 10 European countries (multicenter trial). Oral Surg Oral Med Oral Pathol Oral Radiol Endod 2008; 105(5):597-605. https://doi.org/10.1016/j.tripleo.2007.09.032

[10] Siddiqi KM, Zeeshan Baig M, Awan MJ, Sahibzada HA, Akhtar A. Pattern of medical conditions among patients attending oral and maxillofacial surgery over a period of one year. J Islamabad Med Dent Coll 2016; 5(1):26-9.

[11] Greenberg BL, Glick M, Frantsve J, Kantor ML. Attitudes on screening for medical conditions by oral health care professionals. J Am Dent Assoc 2010; 141:52-62.

[12] Curran AE, Caplan DJ, Lee JY, Paynter L, Gizlice Z, Champagne C, et al. Dentists' attitudes about their role in addressing obesity in patients.A national survey. J Am Dent Assoc 2010; 14(11):1307-16. https://doi.org/10.14219/jada.archive.2010.0075

[13] Forbes K, Thomson WM, Kunzel C, Lalla E, Lamster IB. Management of patients with diabetes by general dentists in New Zealand. J Periodontol 2008; 79(8):1401-8. https://doi.org/10.1902/jop.2008.070640

[14] Greenberg BL, Glick M, Goodchild J, Duda PW, Conte NR, Conte M. Screening for cardiovascular risk factors in a dental setting. J Am Dent Assoc 2007; 138(6):798-04. https://doi.org/10.142 19/jada.archive.2007.0268

[15] Jontell M, Glick M. Oral health care professionals' identification of cardiovascular disease risk among patients in private dental offices in Sweden. J Am Dent Assoc 2009; 140(11):1385-91. https://doi.org/10.142 19/jada.archive.2009.0075

[16] Pooyafared A, Hashemipour MS, Baharloey KH, Shafiei L, Montajeb F. Standardization of European medical risk related history questionnaire for use with Persian-speaking population. J Educ Health Promot 2015; 4:41. https://doi.org/10.4103/2277-9531.157227 
[17] Afifi RM, Saad AE, Zaytoun SS, Afifi Y. A four-year study of chronic patients' information integration in dental and medical documentation in a secondary care setting. Cardiol Angiol Inter J 2017; 6:1-11. https://doi.org/10.9734/CA/2017/30903

[18] Greenberg BL, Kantor ML, Jiang SS, Glick M. Patients' attitudes toward screening for medical conditions in a dental setting. J Public Health Dent 2011; 72(1):28-35. https://doi.org/10.1111/j.1752-7325.2011.00280.x

[19] Sacks FM, Lichtenstein AH, Wu JHY, Appel LJ, Creager MA, Kris-Etherton PM, et al. Dietary fats and cardiovascular disease: a presidential advisory from the American heart association. Circulation 2017; 136(3):e1-e23. https://doi.org/10.1161/CIR.0000000000000510

[20] Greenberg BL, Glick M. Screening for unidentified increased systemic disease risk in a dental setting. Am J Public Health 2012; 102(7):e10. https://doi.org/10.2105/AJPH.2012.300729

[21] Li G, Zhang P, Wang J, Gregg EW, Yang W, Gong Q, et al. The long-termeffect of lifestyle interventions to prevent diabetes in the China Da Qing diabetes prevention study: a 20-year follow-up study. Lancet 2008; 371(9626):1783-9. https://doi.org/10.1016/So140-6736(08)60766-7

[22] Lalla E, Kunzel C, Burkett S, Cheng B, Lamster IB. Identification of unrecognized diabetes and pre-diabetes in a dental setting. J Dent Res 2011; 90(7):855-60. https://doi.org/10.1177/0022034511407069

[23] Friman G, Golestani G, Kalkali A, Wårdh I, Hultin M. Patient experiences of medical screening performed by the dental services: A qualitative study. Open J Stomatol 2013; 3(9):24-32. https://doi.org/10.4236/ojst.2020.104006

[24] Centers for Disease Control and Prevention. National Center for Health Statistics. Health, United States, 2009: with special feature on medical technology. Hyattsville (MD): National Center for Health Statistics (US); 2010.

[25] Nasseh K, Greenberg B, Vujicic M, Glick M. The effect of chairside chronic disease screenings by oral health professionals on health care costs. Am J Public Health 2014; 104(4):744-50. https://doi.org/10.2105/AJPH.2013.301644

[26] Wang WZ, Tang JL. Medical screening: to be or not to be? Chin Med J 2010; 123(14):1948-51.

[27] Bahekar AA, Singh S, Saha S, Molna J, Arora R. The prevalence and incidence of coronary heart disease is significantly increased in periodontitis: a meta- analysis. Am Heart J 2007; 154(5):830-7. https://doi.org/10.1016/j.ahj.2007.06.037

[28] Kaur G, Holtfreter B, Rathmann W, Schwahn C, Wallaschofski H, Schipf S, et al. Association between type 1 and type 2 diabetes with periodontal disease and tooth loss. J Clin Periodontol 2009; 36(9):765-74. https://doi.org/10.1111/j.1600-051X.2009.01445.x

[29] VanDevanter N, Combellick J, Hutchinson MK, Phelan J, Malamud D, Shelley DA. A qualitative study of patients' attitudes toward HIV testing in the dental setting. Nur Res Pract 2012; 2012:803169. https://doi.org/10.1155/2012/803169

[30] Bowyer V, Sutcliffe P, Ireland R, Lindenmeyer A, Gadsby R, Graveney M, et al. Oral health awareness in adult patients with diabetes: A questionnaire study. Br Dent J 2011; $211: \mathrm{E} 12$

[31] Hogan J, Radhakrishnan J. The assessment and importance of hypertension in the dental setting. Dent Clin North Am 2012; 56(4):731-45. https://doi.org/10.1016/j.cden.2012.07.003 